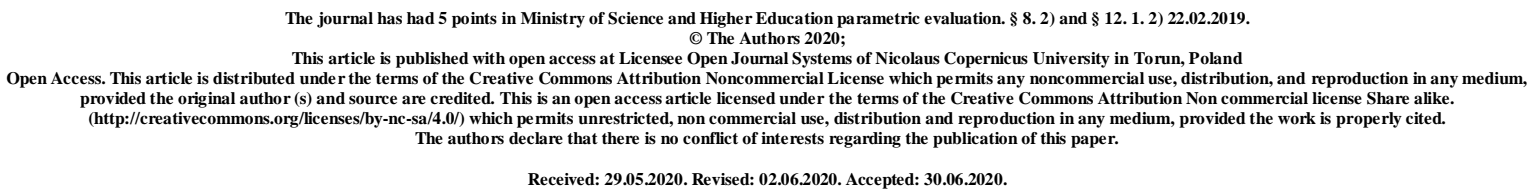

UDC 616.314-092.9:577.152.3

\title{
A COMPARATIVE STUDY ON THE EFFECTIVENESS OF APPLICATION OF DIFFERENT TYPES OF BIOLOGICAL MATRIXES ON MANDIBULAR
} ALVEOLAR MUCOSA LESION HEALING

\author{
H. O. Vyshnevska ${ }^{1}$, Z. Sh. Kakabadze ${ }^{2}$, S. A. Schnayder ${ }^{1}$, L. M. Zayats ${ }^{3}$,
} O. I. Tiron ${ }^{4}$, R. S. Vastyanov ${ }^{4}$

\author{
${ }^{1}$ SI "Institute of Dentistry and Maxillofacial Surgery of the National Academy of \\ Medical Sciences of Ukraine", Odessa, Ukraine; \\ ${ }^{2}$ Tbilisi State Medical University, Tbilisi, Georgia; \\ ${ }^{3}$ Ivano-Frankivsk National Medical University, Ivano-Frankivsk, Ukraine \\ ${ }^{4}$ Odessa National Medical University, Odessa, Ukraine
}

Abstract

Periodontal diseases is one of the most relevant and important problem in modern dentistry due to their increasing prevalence in population, association with the occurrence of focus of chronic infection, progressive development and irreversibility which, in case of severe damage of periodontal tissues, eventually leads to a loss of the number of teeth. All of the named factors eventually lead to the development of irreversible inflammatory-dystrophic and destructive changes in periodontal tissues. During the recent years the method of guided tissue regeneration that uses membranes is being successfully used for the treatment of periodontal diseases. 
A comparative study on the mandibular alveolar mucosa lesion healing during application of different types of biological matrixes containing decellularized amniotic membrane, decellularized amniotic membrane in combination with platelet-rich plasma (PRP) growth factors, and decellularized amniotic membrane in combination with PRP growth factors and hyaluronic acid was performed. The study proved the acceleration of the processes of wound area reduction. Under experimental conditions, the wound healing lasted from day 3 to day 5 of the study; however, the rate of reduction of the wound area was slower, which indicates an alterative stage of the acute inflammatory process. During days $5-7$ (stage of regeneration, the $2^{\text {nd }}$ phase of wound process) the wound area reduced rapidly and by day $14 \mathrm{a}$ complete epithelization of the surgical wound was observed in all groups using decellularized amniotic membrane. In the group using the combination of PRP growth factors and hyaluronic acid the epithelization of wound was already observed on the day 5 . In the control group healing occurres with scar formation.

Key words: amniotic membrane; PRP growth factors; hyaluronic acid; epithelization; wound healing.

\section{Introduction}

Periodontal diseases is one of the most relevant and important problem in modern dentistry [1-4] due to their increasing prevalence in population, association with the occurrence of focus of chronic infection, progressive development and irreversibility which, in case of severe damage of periodontal tissues, eventually leads to a loss of the number of teeth $[2,5-7]$.

Since the etiology of periodontitis is diverse, there are numerous hypotheses regarding the endogenous and exogenous factors causing it. The most significant local factor is the influence of biofilm microflora that includes potential and specific periodontal pathogens [8] accompanied by a shift in oral defense mechanisms [9], masticatory dysfunctions due to abnormalities of jaw development, traumatic occlusion and early teeth loss [10]. Other systemic factors include chronic emotional stress, radiation exposure, insufficient intake of vitamins, micro- and macronutrients, concomitant internal organs pathology, endocrine disorders etc. [1, 11-13].

A long-term influence of the mentioned factors on periodontium and a whole body causes a cascade of neuroregulatory, neurotrophic, biochemical, immunological and functional disorders, affects metabolism and microcirculation [1, 11]. All of them eventually lead to the development of irreversible inflammatory-dystrophic and destructive changes in 
periodontal tissues [9]. The latter is accompanied by disorders in protein, lipid, carbohydrate and mineral metabolism, which determine the multifaceted clinical presentations of the disease. Under such conditions, it may be difficult to choose methods of adequate pharmacological therapy to achieve rapid reduction of inflammation and restore the structure and functions of periodontal tissues [3].

This group of patients is commonly diagnosed with concomitant diseases of the alimentary canal, cardiovascular, endocrine, urinary, nervous system, blood or immune disorders etc. Such systemic diseases may worsen the course of inflammatory-dystrophic process in periodontium, increase the chances of alveolar bone resorption with the decrease of bone mineral density [14]. Under such conditions the course of inflammatory-dystrophic process in the human body is accompanied by the formation of bone and/or epithelial defect. This significantly complicates the course of the main disease, may become a concomitant disease in case of the presence of generalized periodontitis, and should be taken into account when planning the scheme of the complex treatment of certain inflammatory-dystrophic jaw lesion. Evidently, in the latter case the bone and/or epithelial defect must be restored.

During the recent years the method of guided tissue regeneration that uses membranes is being successfully used for the treatment of periodontal diseases $[15,16]$. Nowadays the development of materials which would meet several criteria (in particular delimit the defect area for the whole period of periodontal tissues regeneration and, consequently, prevent the epithelial ingrowth and facilitate osteogenesis) remains a relevant task. The development of organic chemistry has led to real preconditions for the creation of novel synthetic materials with unique properties which can meet the mentioned requirements.

The most commonly used materials for restoration of oral mucosa defects are those that require covering by a mucosal membrane, so they must be sutured and not contact with the environment of oral cavity. A promising direction in the development of new biological materials is the creation of restorative material for the regeneration of oral cavity mucosa that would not require suturing under the mucosal membrane [17-19].

We have also observed the positive regenerative properties of the platelet-rich blood plasma (PRP), which is widely used to increase the concentration of autologous growth factors and secretory proteins. The latter increase the effectiveness of regeneration at the cellular level [20,21]. PRP is known to enhance recruitment, proliferation and differentiation of cells involved in the process of tissue regeneration [22, 23]. There are also known the positive effects of PRP use in patients with mandibular fractures: acceleration of bone repair, prevention 
(or significant delay) of posttraumatic complications development, better overall treatment outcomes, shortened rehabilitation term and decreased term of work ability loss [24].

Considering all the abovementioned, we conducted a series of experimental studies to establish the effectiveness of different types of biological matrixes containing decellularized amniotic membrane (DAM), DAM in combination with PRP growth factors and DAM in combination with PRP growth factors and hyaluronic acid (HA) on regeneration of mandibular alveolar mucosa defect.

Aim of the research: to provide comparative evaluation of the regenerative effectiveness of biological matrixes, containing decellularized amniotic membrane (DAM), DAM in combination with PRP growth factors and DAM in combination with PRP growth factors and hyaluronic acid (HA).

\section{Materials and methods.}

97 male and female Wistar rats weighing 200-250 g were used for the study. The study was approved at the meeting of the Ethics Committee of the Georgian National Institute for Medical Research.

Study design. The animals were divided into 4 groups of 24 each. Oral mucosa defect of the mandibular alveolar process was created in all animals. General anesthesia was administered by intraperitoneal injection of Sodium thiopental $(35 \mathrm{mg} / \mathrm{kg})$. The oval area of the oral mucosa, measuring $3 \mathrm{~mm}$ in diameter, was cut out using surgical scissors without damaging underlying periosteum and bone (Fig. 1).

The first group of 24 rats (12 males and 12 females) was the control one and did not receive any treatment of the created alveolar mucosa defect.

The animals of the second group ( $\mathrm{n}=24,12$ males and 12 females) for regeneration of the bone and epithelial cover in the area of the mandibular alveolar mucosa defect were treated using decellularized rehydrated amniotic membrane (DrAM). DrAM was fixed to the edges of the defect by nodal sutures using atraumatic needle 7/0 ('Ethicon'). The membrane's size and shape were adapted to the size of defect. (Fig. 2).

In 24 animals of the third group (12 males and 12 females) the oral mucosa defect was closed by DrAM with a layer of PRP applied on its surface. The fixation of amniotic membrane was done in the same way as it was described in animals of the second group (Fig.3).

In animals of the fourth group ( $\mathrm{n}=24,12$ males, 12 females) the oral mucosa defect was treated with DrAM with PRP and hyaluronic acid applied on its surface (Fig. 4). 


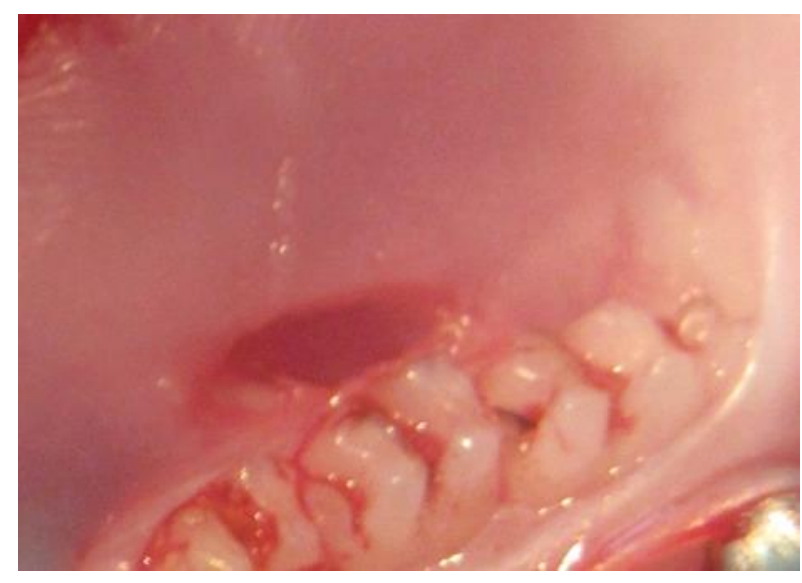

Fig. 1. Defect of the alveolar oral mucosa

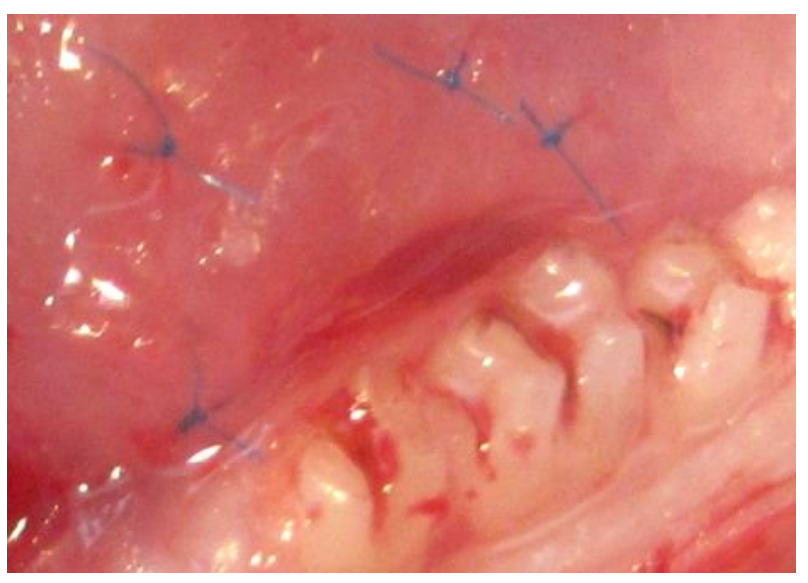

Fig. 2. Defect of the alveolar oral mucosa covered by decellularized rehydrated amniotic membrane

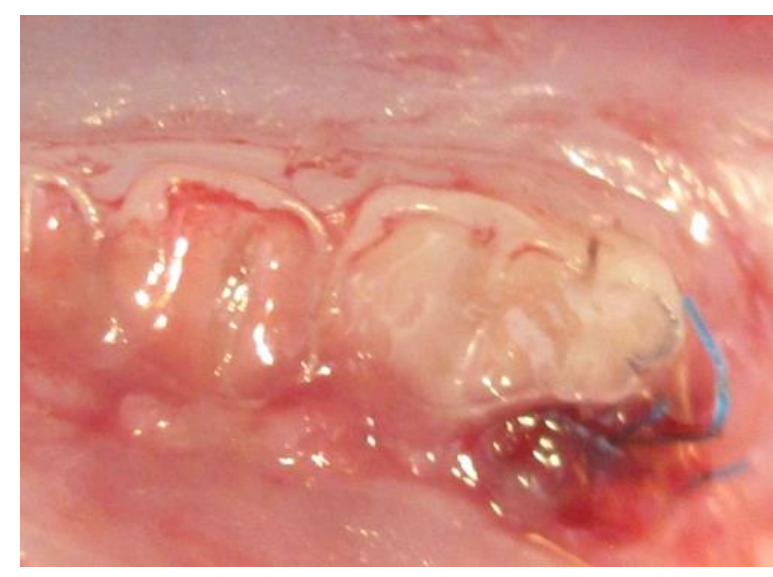

Fig. 4. Oral mucosa defect closed with $\mathrm{DAM}+\mathrm{PRP}+\mathrm{HA}$

After the surgery, all animals were kept under standard vivarium conditions. Animals were euthanized on $3^{\text {rd }}, 5^{\text {th }}, 7^{\text {th }}$, and $14^{\text {th }}$ day after the surgery by administration of intraperitoneal injection of lethal dose of $0,5 \%$ Sodium thiopental solution.

The rate of wound healing by secondary intention was evaluated by measuring its surface area. The rate of wound healing was determined using the formula developed by L.N. Popova [25]: a sterile cellophane plate was applied to the wound and the wound contours were marked. The obtained pattern was transferred to a graph paper and the wound surface area was calculated. Then, the percentage of daily reduction of the wound surface area in relation to a previous result was calculated using the following formula: 


$$
S=\frac{\left(\mathrm{S}-\mathrm{S}_{\mathrm{o}}\right) \times 100}{\mathrm{~S} \times \mathrm{t}}
$$

$\mathrm{S}$ - the value of the wound surface area during previous measurement;

$\mathrm{S}_{\text {。 }}$ - the current value of the wound surface area; $\mathrm{t}$ - the number of days.

During the normal course of the wound healing, the daily reduction of the wound area should be at least $4 \%$.

For the description of clinical characteristics of the wound process, we used classification created by M.I. Kuzin. According to the latter, the wound process occurs in three phases [26]:

1. Inflammation phase which includes two stages: 1) vascular reactions; 2) removal of cell debris and necrotized tissues.

2. Regeneration phase - formation and maturation of connective tissue.

3. Reorganization of scar and epithelization.

Method of PRP preparation. After euthanasia of 1 laboratory rat by the intraperitoneal administration of a lethal dose of $0,5 \%$ sodium thiopental solution, its blood was collected in a test tube which then was placed in centrifuge Kokusan H-9R (Japan). The blood was centrifuged for $20 \mathrm{~min}$ at $29^{\circ} \mathrm{C}(1600 \mathrm{rpm})$. After centrifugation the upper and middle layers of liquid were removed and transferred to a clean tube. The latter was placed in centrifuge again and centrifuged for $15 \mathrm{~min}(400 \mathrm{rpm})$. Thus, it was obtained the plasma divided into 2 fractions: the upper layer - platelet-depleted plasma, the lower layer - plateletrich plasma (PRP).

Method of preparation of biologically active membrane. To obtain a biologically active membrane in combination with PRP growth factors and HA $1 \mathrm{ml}$ of PRP was mixed with $0,5 \mathrm{ml}$ of $\mathrm{HA}$ in a sterile cup. Lyophilized human amniotic membrane was placed in a Petri dish and rehydrated with $0,9 \% \mathrm{NaCl}$ solution for 40 minutes. Then rehydrated amniotic membrane was placed on a sterile table and its anterior surface was covered with PRP with HA. After that, the membrane was inverted and its reverse side was also covered with PRP and HA.

\section{Results}

Bleeding occurred immediately after the creation of gingival mucosa defect. In case of formation of dense fibrinous clot, the bleeding stopped rapidly. The first day after traumatic period was characterized by swelling of the wound tissues, fibrous inflammation with a small amount of serous exudate. On the second day in animals of the control group it was observed 
a notable swelling of surrounding tissues and vascular hyperemia. During the same term, in animals of the $2^{\text {nd }}, 3^{\text {rd }}$, and $4^{\text {th }}$ group it was seen a dense elastic mass under the membrane (Fig. 5, 6).

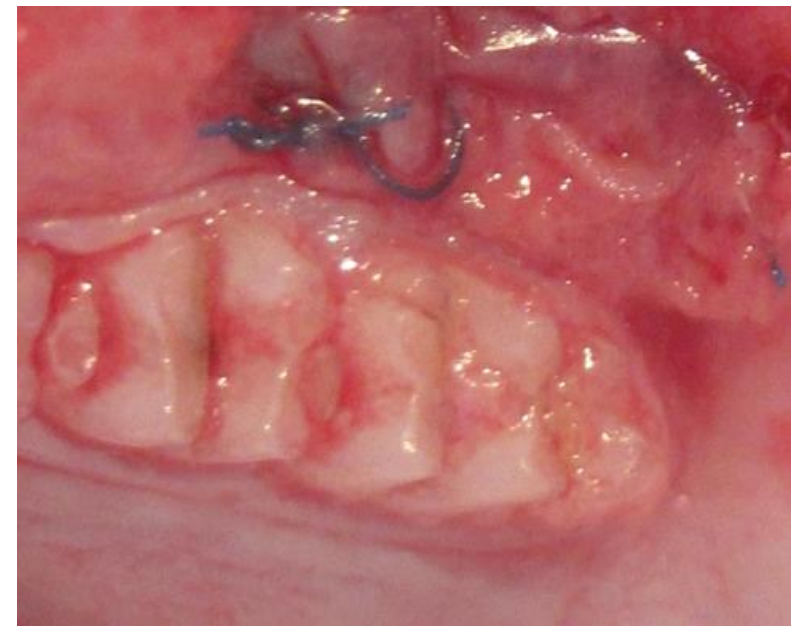

Fig. 5. Photograph. Restoration of alveolar soft tissue defect using DAM. $3^{\text {rd }}$ day of experiment.

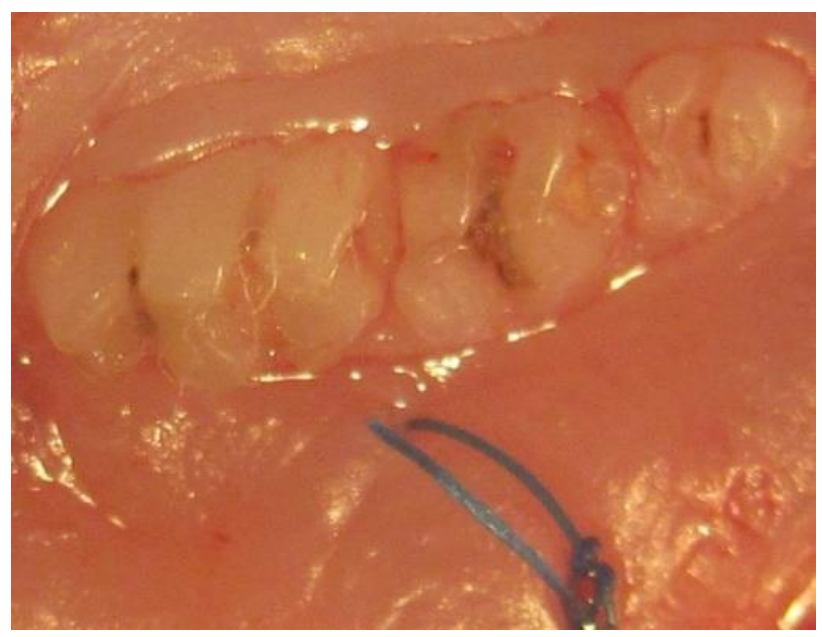

Fig. 6. Photograph. Restoration of alveolar soft tissue defect using DAM+PRP. $3^{\text {rd }}$ day of experiment.

Membrane rejection and formation of pale pink mucosa in animals of experimental groups - with DAM, DAM+PRP, and DAM+PRP+HA were observed on $3-5^{\text {th }}$ day of experiment (Fig. 7, 8). While in animals of the control group the scab still remained on the wound surface.

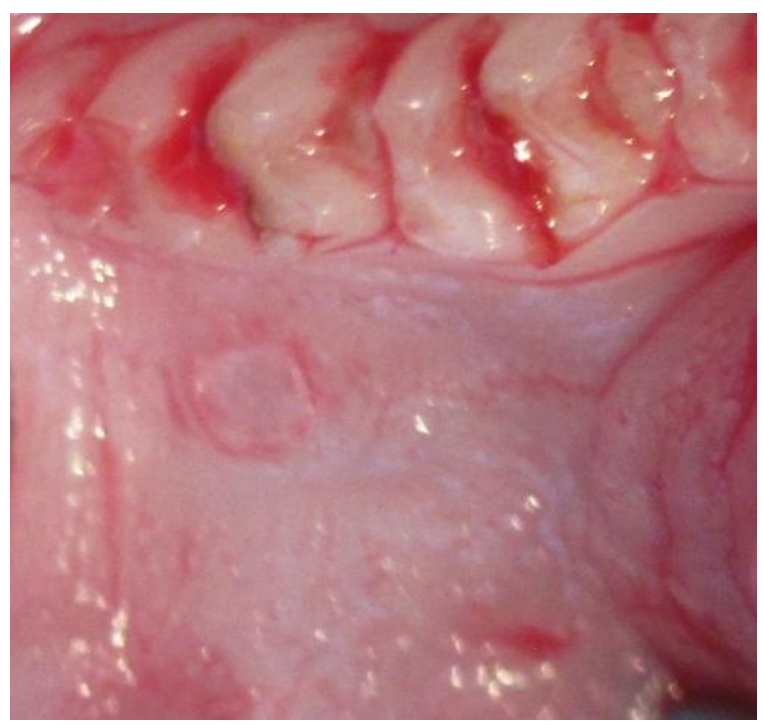

Fig. 7. Photograph. Membrane rejection in animals with DAM + PRP. $3^{\text {rd }}$ day of experiment.

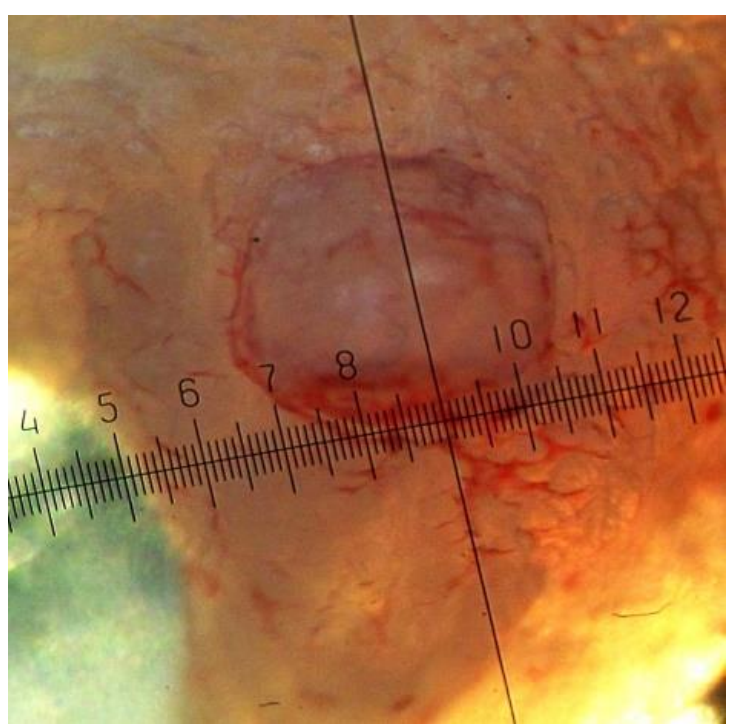

Fig. 8. Photograph. Membrane rejection in animals with DAM + PRP+HA. $3^{\text {rd }}$ day of experiment. 
Complete visual healing of wounds with regeneration of mucosal defect's wound surface in rats of the second group (treated with DAM) was observed on the $7^{\text {th }}$ day, in animals of the third group (DAM+PRP) - on the $5^{\text {th }}$ day, in animals of the fourth group (DAM+PRP+HA) - on $4-5^{\text {th }}$ day after trauma (Fig. 9, 10).

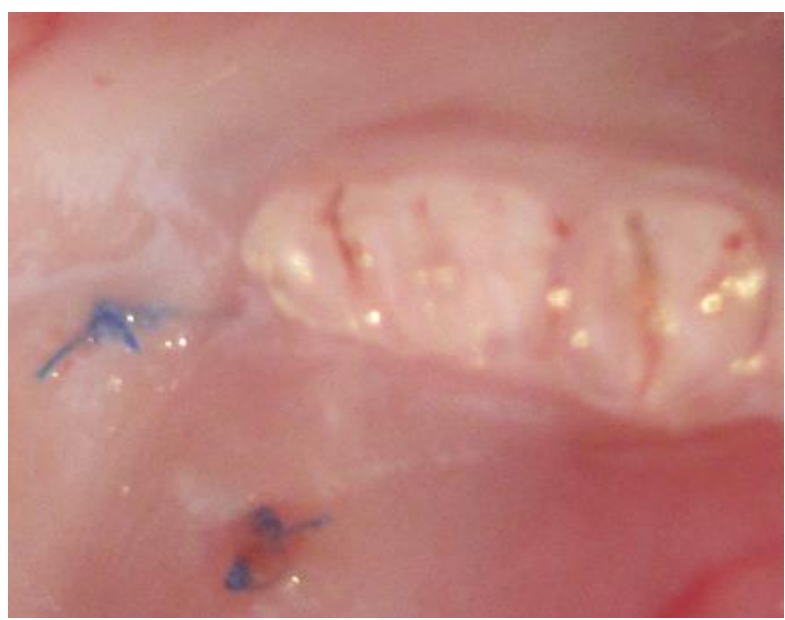

Fig. 9. Photograph. Regeneration of the

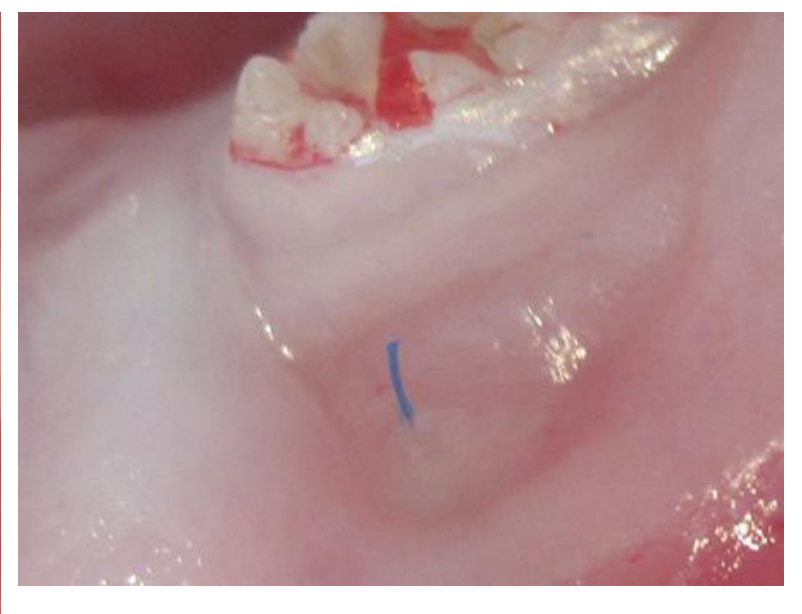

Fig. 10. Photograph. Regeneration of the alveolar soft tissues defect in dynamics using alveolar soft tissues defect in dynamics using

DAM+PRP.

$5^{\text {th }}$ day of experiment.
$\mathrm{DAM}+\mathrm{PRP}+\mathrm{HA}$.

$5^{\text {th }}$ day of experiment.

The analysis of the dynamics of surgical wound healing using L.N. Popova's formula revealed the following:

a) in the second experimental group the daily reduction of the surface area of defect comprised $6,6 \%$ on the $3^{\text {rd }}$ day, $5,3 \%$ on the $5^{\text {th }}$ day and $4,8 \%$ on the $7^{\text {th }}$ day;

b) in the third group of animals (DAM+PRP) the studied value was $8,8 \%$ on the $3^{\text {rd }}$ day, $6,6 \%$ on the $5^{\text {th }}$ day, $6,1 \%$ on the $7^{\text {th }}$ day;

c) in the fourth group (DAM+PRP+HA) the daily reduction of the surface area of defect comprised $8,8 \%$ on the $3^{\text {rd }}$ day, $8 \%$ on the $5^{\text {th }}$ day, $6,6 \%$ on the $7^{\text {th }}$ day. These data indicate that from the $3^{\text {rd }}$ to the $5^{\text {th }}$ day of pathological process the rate of the wound surface area reduction is lower. The latter indicates the phase of inflammation (Table 1).

Later, after the beginning of the second (regeneration) phase of the wound healing $\left(5^{\text {th }}-7^{\text {th }}\right.$ day) the wound surface area reduced rapidly and by the $14^{\text {th }}$ day the complete epithelization of surgical wound was observed in all groups.

In the control group during $3^{\text {rd }}-5^{\text {th }}$ days of experiment the percentage of the daily reduction of wound surface area was less than $4 \%$, indicating prolonged wound process with 
alternating periods of exacerbation and remission, increased granulation and delayed epithelization.

Table 1

The percentage of the daily reduction of surgical wound surface area

\begin{tabular}{|c|c|c|c|c|c|c|c|c|c|c|c|c|}
\hline \multirow{2}{*}{$\begin{array}{l}\text { Experimental } \\
\text { group / Day of } \\
\text { experiment }\end{array}$} & \multicolumn{3}{|c|}{ Control } & \multicolumn{3}{|c|}{ DAM } & \multicolumn{3}{|c|}{ DAM+PRP } & \multicolumn{3}{|c|}{ DAM+PRP+HA } \\
\hline & 3 & 5 & 7 & 3 & 5 & 7 & 3 & 5 & 7 & 3 & 5 & 7 \\
\hline $\begin{array}{l}\text { Daily reduction of } \\
\text { the wound surface, } \\
\%\end{array}$ & 2,2 & 2,6 & 2,9 & 6,6 & 5,3 & 4,8 & 8,8 & 6,6 & 6,1 & 8,8 & 8,0 & 6,6 \\
\hline
\end{tabular}

From the $5^{\text {th }}$ to $7^{\text {th }}$ day the percentage of the daily reduction of wound surface area slightly increased to $2,9 \%$ (table 1 ), which may suggest the beginning of reorganization phase and the final formation of scar tissue by the $14^{\text {th }}$ day.

\section{Conclusions}

1. In all four groups the regeneration of the surgical wound occurred by the $14^{\text {th }}$ day.

2. The epithelization occurred more rapidly in the third and fourth groups in comparison with the second group. On the $3^{\text {rd }}$ day, the percentage of the daily reduction of surgical wound surface area comprised $8,8 \%$ in the $3^{\text {rd }}$ and $4^{\text {th }}$ groups; and $6,6 \%$ in the second group.

3. In the control group, in which regeneration took place without using biological membranes, the wound healing was more prolonged, and accompanied by the inhibition of granulation formation and subsequent scar formation in the area of the alveolar mucosal defect.

4. In further studies the potential for layered epithelization of soft tissue defects will be examined using histological methods of research and evaluation of the restoration of blood circulation in the surgical wound area.

\section{References:}

1. Jiménez-Sánchez M.C., Cabanillas-Balsera D., Areal-Quecuty V., VelascoOrtega E., Martín-González J., Segura-Egea J.J. Cardiovascular diseases and apical periodontitis: association not always implies causality. Med. Oral Patol. Oral Cir. Bucal. 2020; 25(5): 652-659. 
2. Pietropaoli D., Monaco A., D'Aiuto F., Muñoz Aguilera E., Ortu E., Giannoni M., Czesnikiewicz-Guzik M., Guzik T.J., Ferri C., Del Pinto R. Active gingival inflammation is linked to hypertension. J. Hypertens. 2020; 38(10): 2018-2027.

3. Scannapieco F.A., Gershovich E. The prevention of periodontal disease - An overview. Periodontol. 2000. 2020; 84(1): 9-13.

4. Sczepanik F.S.C., Grossi M.L., Casati M., Goldberg M., Glogauer M., Fine N., Tenenbaum H.C. Periodontitis is an inflammatory disease of oxidative stress: We should treat it that way. Periodontol 2000. 2020; 84(1): 45-68.

5. Du Q., Ma X. Research progress of correlation between periodontal pathogens and systemic diseases. Nan Fang Yi Ke Da Xue Xue Bao. 2020; 40(5): 759-764.

6. Wang M., Xie J., Wang C., Zhong D., Xie L., Fang H. Immunomodulatory Properties of Stem Cells in Periodontitis: Current Status and Future Prospective. Stem Cells Int. 2020; 2020: 9836518. doi: 10.1155/2020/9836518. eCollection 2020.

7. Wang J., Yang X., Zou X., Zhang Y., Wang J., Wang Y. Relationship between periodontal disease and lung cancer: A systematic review and meta-analysis. J. Periodontal Res. 2020; 55(5): 581-593.

8. Kushkevych I., Coufalová M., Vítězová M., Rittmann S.K.R. Sulfate-Reducing Bacteria of the Oral Cavity and Their Relation with Periodontitis-Recent Advances. J. Clin. Med. 2020; 9(8): 2347. doi: 10.3390/jcm9082347.

9. Möller B., Kollert F., Sculean A., Villiger P.M. Infectious Triggers in Periodontitis and the Gut in Rheumatoid Arthritis (RA): A Complex Story About Association and Causality. Front Immunol. 2020 ; 11: 1108. doi: 10.3389/fimmu.2020.01108. eCollection 2020.

10. Foz A.M., Artese H.P., Horliana A.C., Pannuti C.M., Romito G.A. Occlusal adjustment associated with periodontal therapy--a systematic review. J. Dent. 2012; 40(12):1025-1035.

11. Beck J.D., Papapanou P.N., Philips K.H., Offenbacher S. Periodontal Medicine: 100 Years of Progress. J. Dent. Res. 2019; 98(10): 1053-1062

12. Krawiec M., Dominiak M. The role of vitamin D in the human body with a special emphasis on dental issues: Literature review. Dent. Med. Probl. 2018; 55(4): 419-424

13. Woelber J.P., Tennert C. Chapter 13: Diet and Periodontal Diseases. Monogr. Oral Sci. 2020; 28: 125-133.

14. Gruber R. Osteoimmunology: Inflammatory osteolysis and regeneration of the alveolar bone. J. Clin. Periodontol. 2019; 46(21): 52-69 
15. Omar O., Elgali I., Dahlin C., Thomsen P. Barrier membranes: More than the barrier effect? J. Clin. Periodontol. 2019; 46 (Suppl Suppl 21): 103-123.

16. Zhuang Y., Lin K., Yu H. Advance of Nano-Composite Electrospun Fibers in Periodontal Regeneration. Front. Chem. 2019; 7: 495. doi: 10.3389/fchem.2019.00495. eCollection 2019.

17. Al-Khateeb R., Prpic J. Hyaluronic acid: the reason for its variety of physiological and biochemical functional properties. Appl. Clin. Res. Clin. Trials Regul. Aff. 2019;6:112-159.

18. El Sheshtawy A.S., Nazzal H., El Shahawy O.I., El Baz A.A., Ismail S.M., Kang J., Ezzat K.M. The effect of platelet-rich plasma as a scaffold in regeneration/revitalisation endodontics of immature permanent teeth assessed using 2dimensional radiographs and Cone Beam Computed Tomography: A randomised controlled trial. Int. Endod. J. 2020; 53(7): 905-921.

19. Wilshaw S.P., Kearney J.N., Fisher J., Ingham E. Production of an acellular amniotic membrane matrix for use in tissue engineering. Tissue Eng. 2006; 12: 2117-2129.

20. Alagl A., Bedi S., Hassan K., Al Humaid J. Use of platelet-rich plasma for regeneration in non-vital immature permanent teeth: clinical and cone-beam computed tomography evaluation. J. Int. Med. Res. 2017; 45, 583-593.

21. Bezgin T., Yilmaz A.D., Celik B.N., Kolsuz M.E., Sonmez H. Efficacy of platelet-rich plasma as a scaffold in regenerative endodontic treatment. J. Endodontics. 2015; 41: 36-44.

22. Anitua E., Sanchez M., Merayo-Lloves J., De la Fuente M., Muruzabal F., Orive G. Plasma rich in growth factors (PRGF-Endoret) stimulates proliferation and migration of primary keratocytes and conjunctival fibroblasts and inhibits and reverts TGFbeta1-Induced myodifferentiation. Invest. Ophthalmol. Vis. Sci. 2011; 52(9): 6066-6073.

23. Holmes H.L., Wilson B., Goerger J.P., Silverberg J.L., Cohen I., Zipfel W.R., Fortier L.A. Facilitated recruitment of mesenchymal stromal cells by bone marrow concentrate and platelet rich plasma. PLoS One. 2018; 3(3): e0194567. doi: 10.1371/journal.pone.0194567. eCollection 2018.

24. Castillo-Cardiel G., Medina-Quintana V.M., Lomelí-Enríquez M., MedranoMuñoz F., Guerrero-Velázquez C., Contreras-López C.K., Fuentes-Orozco C., IrustetaJiménez L., Michel-Espinoza L.R., González-Ojeda A. Platelet-rich plasma and its effect in bone regeneration in mandibular fractures. Controlled clinical trial. Gac. Med. Mex. 2017; 153(4): 459-465. 
25. Popova L.N. How the boundaries of the formed epidermis change during wound healing. $\mathrm{PhD}$ (Med) Thesis. Voronezh. 1942: 14 p [In Russian].

26. Kuzin M.I., Kostyuchenok B.A. Wounds and Wound Infection: A Guide for Physicians. Medicine: Moscow, 1990: 592 p [In Russian]. 